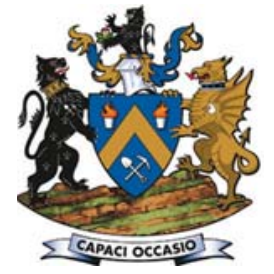

Affiliation:

${ }^{1}$ School of Law, University of the Witwatersrand, South Africa.

Correspondence to:

K. Thambi

Email:

Kiyasha.Thambi@wits.ac.za

Dates:

Received: 15 Mar. 2018

Revised: 12 Dec. 2018

Accepted: 15 Jan. 2019

Published: May 2019

How to cite:

Thambi, K

Mining companies attain relief

through deductions on infrastructure relating to Social and Labour Plans: A case of the cart before the horse?

The Southern African Insitute of Mining and Metallurgy

DOI ID:

http://dx.doi.org/10.17159/24119717/61-132-1/2019

ORCiD ID:

K. Thambi

https://orchid.org/0000-0003-

4456-3027

\section{Mining companies attain relief through deductions on infrastructure relating to Social and Labour Plans: A case of the cart before the horse?}

\section{K. Thambi ${ }^{1}$}

\section{Synopsis}

A recent amendment to Section 36(11) (e) of the Income Tax Act, 53 of 1968 (Tax Act) now extends the allowable deduction of 'capital expenditure' incurred by mining companies pursuant to the Mineral and Petroleum Resources Development Act 28 of 2002 (MPRDA). In terms of the Taxation Laws Amendment Bill 2016 (TLAB 2016), the allowable deduction has been extended to include expenditure incurred on infrastructure in terms of Social and Labour Plan (SLP) requirements as per the MPRDA. Interestingly, what necessitated the amendment was the need to recognize SLP requirements and to circumvent administrative difficulties for mining companies and the South African Revenue Services (SARS) in differentiating the use of developmental infrastructure by employees or the community. The successful implementation of such a deduction hinges on a sound SLP system. However, given the challenges within the current SLP system, this amendment could be considered somewhat premature.

\section{Keywords}

Social and Labour Plan, capital expenditure, infrastructure, tax relief.

\section{Introduction}

Section 36(11) of the Income Tax Act 58 of 1962 (Tax Act) enabled mining companies to deduct certain capital expenditure in lieu of its other sections. In particular, it made provision for mining companies to deduct capital expenditure incurred pursuant to the Mineral and Petroleum Resources Development Act 28 of 2002 (MPRDA), but excluding capital expenditure incurred in respect of infrastructure or environmental rehabilitation. As such, mining companies could only deduct such capital expenditure that related directly to their employees and not to the wider community (Clegg, 2018).

In terms of the Taxation Laws Amendment Bill 2016 (TLAB, 2016) (South Africa, 2016a), the recent amendment to Section 36 extends the relief provided under section 36(11) (e) to include capital expenditure incurred on infrastructure in terms of the Social and Labour Plan (SLP) requirements of the MPRDA. In other words, the capital expenditure incurred by the mining company for the benefit of the people living in mining communities. To qualify for such a deduction, the infrastructure erected or developed by the mining company should reflect what was agreed between the mining company and the Department of Mineral Resources (DMR) as per the SLP requirements of the MPRDA (TLAB 2016).

\section{The Problem}

Considering the current SLP system, there are significant disparities between its various stakeholders as well as limitations, i.e. current guidelines on the development of SLPs have proven insufficient, the interpretations of SLP requirements lack standardization and proper guidance, and there is a lack of implementation and active participation by various stakeholders (among others). Therefore, the deduction granted in terms of Section 36(11) (e) is in all likelihood premature, possibly based on insufficiencies in information, leading to premature approvals of SLPs and/ or approval of SLPs that fall short of the requirements as per the MPRDA and the tenets of SLPs.

Aim

This paper reviews some of the salient disparities that seem to support the notion that the aforementioned amendment may be premature, given the landscape of the current SLP system.

\section{Background: the mining industry and its socio-economic development impact}

The South African mining industry is one of the major building blocks in South Africa's economy. Prior to the new constitutional era, the mining sector was premised on the exploitation of South Africa's mineral 


\section{Mining companies attain relief through deductions on infrastructure}

resources, creating only indirect benefits for the majority of South Africans through the infrastructure and the economy it established (Kloppers and du Plessis, 2008). Not only does the mining industry contribute to South Africa's GDP via exports etc., but it employs a significant number of the population. Despite being a contributor to exports revenue, employment, and infrastructure, it is responsible for a plethora of negative impacts i.e. disputes over land use, pollution, high fatality and injury rates (Finweek Report, 2008), and the impact of mine closure. Yet it has often dismissed its environmentally and socially disruptive business consequences on the basis of cost-benefit analysis; arguing that the monetary benefits outweigh the negative impacts of 'doing business' (Jenkins and Yakovleva, 2006).

As such, the legacy of the mining industry in South Africa has been plagued with controversy given these negative impacts, imbalances between mineworkers, communities, and mining companies. Like a festering wound, this industry has been riddled with the exploitation of a low-wage migrant labour force of black South Africans (Centre for Applied Legal Studies, 2016). Furthermore, the historical tension between mining companies and the communities within which they operate stemmed from the inequity of apartheid, since 'the activities of the mining houses were inextricably linked with colonial, and subsequently apartheid, policies through the migrant labour system' (Hamann, 2003).

In the light of the aforementioned, the South African mining industry, deeply entrenched in the bedrock of South Africa's economy, has faced numerous pressures of varying degrees over the 'extent' of its failure to consider the environment and the communities in which it engages in mining operations. Being a largely capital-intensive industry, with high start-up costs and various regulatory requirements, it is constantly challenged to balance this and regulatory intensive operations with the sustainable integration of some of these pressures i.e. Corporate Social Responsibility (CSR) through SLPs, into its core business strategy. Yet it is evident that some mining companies still view this social investment as a means of gaining their social licence to operate (Hamman, 2003).

On average, a mining company incurs a wide range of expenditure in conducting its operations, including current expenditure (deductible in terms of the general deduction formula per the Tax Act) and capital expenditure. The capital expenditure provisions of the Tax Act provide for the immediate deduction of capital expenditure and of expenditure on prospecting and incidental operations. Capital expenditure includes expenditure on shaft sinking, mine equipment, development, general administration, and management. Some assets, such as housing for residential accommodation, motor vehicles for the private use of employees, and some railway lines and pipelines, qualify only for a partial annual redemption (Clegg, 2018). Prior to the aforementioned amendment, Section 36(11) of Tax Act enabled mining companies to deduct certain capital expenditure in lieu of other sections in the Act. In particular, section 36(11)(e) of the Act made provision for mining companies to deduct capital expenditure incurred pursuant to the MPRDA, but excluded capital expenditure incurred in respect of infrastructure or environmental rehabilitation (Explanatory Memorandum on the Draft Taxation Laws Amendment Bill 17B 2016) (South Africa, 2016b). However, the dilemma for mining companies was that they could deduct such capital expenditure only to the extent that it related directly to employees, and not to the wider community.

\section{The Mineral and Petroleum Resources Development Act 28 of 2002}

Against this backdrop, South Africa's economic transition as an emerging market economy 'eclipsed' plans to resuscitate the economy in favour of growth and development. However for the mining industry in particular; even with Constitution of the Republic of South Africa, Act 108 of 1996 (the Constitution) (South Africa, 1996), which recognizes the State's obligation to protect citizens' socio-economic rights such as the right to housing, clean water, and medical assistance, it was not without limitation (Busacca, 2013). Furthermore, the government was challenged by a lack of resources and skilled personnel (Kloppers and du Plessis, 2008). As such, given the political climate in the country, the transformation was inevitable. To circumvent the destabilization of the mining industry, and inculcate transformation in the mining sector, a number of initiatives were established. One such initiative was the MPRDA, administered by the Department of Mineral Resources (DMR) (Cawood, 2004).

The MPRDA was intended to achieve equitable access to, and sustainable development of, South Africa's mineral and petroleum resources. It vests mineral rights in the State as custodian of the mineral wealth (MPRDA, Government Gazette, 2002). Among its multiple purposes, the MPRDA aims to transform the mining and production industries in South Africa. It focuses on the transformation of the minerals and mining industry with specific emphasis on developing black ownership of mines (Munnik, 2010). The MPRDA requires companies to convert their old-order mining rights into new-order rights. To achieve this, companies must meet a number of social and labour targets that overlap with the targets in the Broad-Based Socio-Economic Empowerment Charter for the South African Mining Industry 2003 (Mining Charter) (Cawood, 2004). For CSR, the most important objective of the MPRDA is contained in Section 2(i), which requires that mining companies contribute toward the socio-economic development of the areas in which they operate (Kloppers and du Plessis, 2008) However, it does not explicitly state how this objective should be achieved, and consequently it is left to the industry to adopt the spirit of the Act in a 'meaningful way'. It would, therefore, appear that the mining industry is often left 'unattended' in its adoption of the spirit of the MPRDA in this regard (Centre for Applied Legal Studies, 2016).

The extent to which mining companies subscribe to the MPRDA is voluntary and is visible by the extent of their CSR programmes. In compliance with the MPRDA, when applying for a new mining right, a company must submit a mine works plan, environmental management plan, and a Social and Labour Plan. Mining operations are further required to submit annual compliance reports (Centre for Applied Legal Studies, 2016). As part of its mandate and endeavour toward effective transformation, the MPRDA makes it compulsory for mining companies to submit a Social and Labour Plan (SLP). In terms of the MPRDA, taxpayers seeking to acquire mineral rights are required to submit a SLP in terms of which the mineral right holder is required to assist local communities with infrastructure and other amenities. The challenge with the SLP is that where infrastructure was built for the benefit of non-employees, such expenditure is treated as non-deductible capital expenditure for income tax purposes.

Simultaneously, when applying for a mining license, mining companies are required to conduct a Social Impact Assessment (SIA) to estimate the social consequences that ensue from their mining activities from start to beyond mine closure. SIAs form 


\section{Mining companies attain relief through deductions on infrastructure}

part of the Environmental Impact Assessment (EIA) process, attempting to review the social impact of a mining project in consideration of the social environment. However SIAs receive far less focus then they should, given their extent. This is due to the fact that the links between environmental and social impacts are not recognized in the mining sector (Creative Space Media, 2015).

\section{Insights into the landscape of Social and Labour Plans}

SLPs are entered into between the mining company, community, and the DMR. The eligibility for a mining right and renewal thereof is conditional upon the submission by a mining company of a SLP, developed in consultation with affected communities. It contains commitments to the DMR in respect of human resources and local economic development. Upon granting of the mining right, these programmes become binding conditions. In other words, noncompliance with the SLP can lead to the suspension of the mining right. Interestingly, what is not clear in the existing legislation is that each SLP contains commitments over a five-year cycle (Centre for Applied Legal Studies, 2016). The tenets of a SLP are to assist with the development of mining communities. This typically involves a company agreeing to build infrastructure, ranging from roads and drainage systems to crèches, schools, clinics, housing, and recreational facilities - to benefit workers and communities surrounding the mine (South Africa, 2016b). The basis of the SLP system is very much a 'carrot-and-stick approach'. The State's approval (or not) of the right to mine is dependent on mining companies, either directly or indirectly from the resources in their area being mined, creating opportunities for mineworkers and communities to benefit (Centre for Applied Legal Studies, 2016).

Furthermore, mining companies are expected to specifically document their implementation of and compliance with the SLP at various stages in the process. Thereafter they are required to deliver on each undertaking, and to the extent that a SLP falls short of its targets the consent of the Minister of Mineral Resources must be obtained by the mining right holder to amend such SLP. Companies are also required to engage with municipalities and participate in the drafting of Integrated Development Plans (IDPs) which are regulated by the Municipal Systems Act 32 of 2000 (Centre for Applied Legal Studies, 2016). In other words, the Local Economic Development (LED) component of the SLP must be aligned with the municipal IDP. The thinking behind this alignment is that such engagement provides opportunities for investment, economic growth, poverty alleviation, and infrastructural development (Creative Space Media, 2015).

Having considered the landscape of the SLP system (whereupon this amendment is reliant), it is clear that there are four significant stakeholders, i.e. mining companies, the DMR, local government, and workers and communities. The disparities between these various stakeholders with regard to responsibilities, expectations, and/or perceptions in the initiation and implementation of SLPs is very evident, as will be seen below. Furthermore, according to the Centre for Applied Legal Studies (2016) 'there is growing evidence that the SLP system does not work and that SLP obligations are not being met'. To support this notion, at the National Council of Provinces (NCOP) the Minister of Mineral Resources stated that as at 31 March 2015 , a total of 240 mining right holders failed to comply with their SLPs. An illustration thereof (though this will not be discussed in detail) is evidence per the Marikana Commission of Enquiry which heard submissions regarding Lonmin's compliance with its SLP, following the Marikana massacre.

\section{SLP stakeholders, the MPRDA and current practices}

\section{Mining companies}

In practice, mining companies do not consult with communities and workers with regard to SLPs and/or amendments thereto. This leads to a fundamental imbalance of the tenets of the SLP system, and at times a possible derogation from the initial commitments made by mining companies, as per their SLP mandate. Consequently, participation and/or stakeholder engagement through the SLP cycle is compromised, particularly since mining companies fail to identify and understand the affected communities, while they pursue their strategic business objectives (CSI, 2015). This lack of stakeholder engagement creates challenges in informing the process leading up to a viable and sustainable SLP. Hence, under such circumstances, mining companies that fail to implement an SLP in line with the MPRDA and SLP guidelines should not be allowed to rely on a tax deduction in terms of Section 36 of the Tax Act. Hence, a claim for a deduction for capital expenditure on infrastructure in relation to a SLP ought to fail where this requirement has not been fully complied.

\section{The DMR}

The DMR has the most significant role of national government departments. It is tasked with managing the mining application process, and the responsibility of monitoring compliance with and enforcement of regulatory requirements, including the approval of SLPs. It is also required to collaborate with various stakeholders to ensure the SLP implementation, which includes the reviewing and approval of applications as well as on-site inspections to verify compliance. Where noncompliance with SLPs is detected, the DMR must use its powers of enforcement, including remedial actions, notices, and (where necessary) suspension or revocation of the mining right (Centre for Applied Legal Studies, 2016). However, the process of SLP evaluation by the DMR is currently inconsistent due to the lack of expertise in evaluating such SLPs. This inconsistency causes undue pressure and weakens the process meant to establish alignment between the strategic objectives of government and mining companies. Fundamentally, the regulatory system does not sufficiently provide clear contextual considerations by which the regulator can evaluate the adequacy and or efficacy of SLPs (Centre for Applied Legal Studies 2016). This will further create a challenge for a mining company claiming a deduction of capital expenditure in relation to infrastructure for a SLP, particularly where reliance is placed on the DMR vetting and approving the claim. To the extent that mining companies are successful in claiming the deductions but have not provided the infrastructure as per SLP requirements, there ought to be misalignment between the SLP and the actual infrastructure built by the mining company. This will create a ripple effect, and an administrative burden for SARS to audit and reconcile deductions granted versus the actual SLPs implemented (tangible). Furthermore, it may require some mining companies to refund any deductions granted prematurely.

\section{Local government}

Local government is mandated with the implementation of LED in terms of both the Constitution and legislation. Each municipality is tasked with drawing up an IDP, being a strategic plan for the development of the municipality (Centre for Applied Legal Studies, 2016). It has been argued that municipalities are the ideal entities to observe the delivery or lack thereof concerning LED projects. This is due to their local knowledge and historical 


\section{Mining companies attain relief through deductions on infrastructure}

relationships with the areas being mined (Creative Space Media, 2015). However, the local government fails in implementing the SLPs due to various factors, e.g. lack of technical capacity, resources, and insufficient infrastructure to support the aims of SLPs. This is exacerbated by municipalities' budgetary constraints and poor delivery of basic services to communities (Centre for Applied Legal Studies, 2016). This is yet another challenge to the SLP system. This lack of engagement between mining companies and local government thwarts any possibility of facilitating opportunities for economic growth, infrastructural development, and poverty alleviation. As consequence thereof, mining companies operate in a void when it comes to the implementation of SLPs that are clearly not a core competency of theirs.

\section{Mineworkers and communities}

Mineworkers and communities who reside near the mining areas are the beneficiary stakeholders of the SLP system, who are acutely affected by the negative environmental, social, and economic impacts of mining. As stated earlier, a prerequisite of the SLP system is that these stakeholders be consulted and taken into consideration on issues that affect them with regard to SLPs. However, in practice, these stakeholders are not consulted, neither are they involved in the process leading to the compilation of an SLP. In fact, they 'fall through the cracks' of the already compromised SLP system where proper stakeholder engagement from both mining companies and local municipalities has failed (Centre for Applied Legal Studies, 2016). As such, they cannot be considered beneficiaries of any socio-economic development when their fundamental rights are compromised. In the light thereof, any claim for a deduction as per Section 36(11) (e) must at least have passed through this basic requirement, failing which the deduction should not even be considered. The challenge, however, is that failure to comply with and monitor the satisfaction of this particular prerequisite by the DMR may be the very reason for SLPs to be prematurely vetted and approved, resulting in an ensuing 'justifiable' deduction per Section 36(11) (e).

\section{Putting the cart before the horse}

There is no doubt that SLPs have tremendous potential under the optimal regulatory conditions, yet it is clear that some of the aforementioned challenges weaken the SLP system in its current state. Hence, it is argued that the basis upon which the Section 36 amendment is founded is fundamentally flawed, in that it suffers from inactive participation by various stakeholders as well as poor implementation (Creative Space Media, 2015). As stated earlier, the current guidelines on the development of SLPs have proven insufficient. The interpretations of SLP requirements require standardization to ensure proper guidance for all stakeholders when executing these plans. In addressing these issues, consideration ought to be given to the application of governance principles in the implementation cycle of SLPs. Furthermore, the SLP system, which was designed to achieve a social impact through mandating the allocation of resources, can be successful only if the required actions by all stakeholders are fulfilled (Centre for Applied Legal Studies, 2016).

Government's role as a primary social service provider has repeatedly come under scrutiny with regard to the implementation of SLPS. This is because the law does not provide detailed guidance on the role of community participation in SLPs. This is controversial, since the SLPS, and the LED section in particular, should be based on the needs and interests of community members. Furthermore, mining companies do not always view SLPs as core to their business, as further evidenced by their SLPs not being linked to their Social Impact Assessments (SIAs) (Centre for Applied Legal Studies, 2016). Hence, compliance with SLPs requires the State to regard them as binding and not persuasive or discretionary. However, the challenge is that the DMR lacks the critical skilled personnel to intensify enforcement of SLP obligations and sanction noncompliance (Centre for Applied Legal Studies, 2017).

This is further supported by the findings of the Centre for Applied Legal Studies in its latest Social and Labour Plan Series, which indicates the following findings (among others):

> The current guidelines on SLPs have proven to be inadequate, in that although they address the content of SLPs, the guidelines are not hard law and thus cannot function as a prescriptive framework.

> In their design, operation, amendment, and termination, the majority of SLPs showed no support for a plan of community participation.

> SLPs showed limited engagement with social and economic dynamics in mining areas and how these informed the design of SLP projects.

$>$ SLPs were difficult to obtain or access (Centre for Applied Legal Studies, 2017).

\section{Conclusion}

It is said that 'South African government departments; and in this instance the DMR, Water Affairs, and local government have a progressive legislative base for mining, yet due to constraints, the capacity for regulating and monitoring compliance is limited' (Munnik, 2010). Much has changed in how the extractive industry responds to social and community issues, with growing prioritization of community-related issues. This can be attributed partly to pressures on mining companies to take a greater responsibility for the social, economic, and environmental impacts of mining, as well as the risks facing the mining and metals industry, in securing and maintaining the social licence to operate (Coulson, Ledwaba, and McCallum, 2017). Mining companies have more resources and capacity than government, resulting in efficiencies and innovation that surpass regulatory compliance. However, this diminishes government's regulatory responsibilities. To this extent, the mining industry is given powerful incentives for voluntary self-regulation. As such, there is tremendous potential for partnership between direct State intervention and business voluntarism regarding CSR and SLPS (Hamann, 2013).

An amendment such as that of Section 36(11) (e) is duly recognized given the constraints on mining companies to give effect to SLPs. Furthermore, the responsibility placed on mining companies to contribute to local economic development imperatives favours SLPs. Equally, it creates an unreasonable expectation that mining companies solve imbalances of socioeconomic development in South Africa but with 'one hand tied behind their back' (Hamann, 2003). Any legislation governing CSR and SLPs demands a greater focus in the long term on governance in social investment, especially since good governance underpins all effective social investment. The DMR will have to consider the inefficiencies during evaluation of SLPs submitted to their provincial offices and SLPs should be accessible to communities, in addition to ensuring monitoring of SLP implementation in their surrounds. 


\section{Mining companies attain relief through deductions on infrastructure}

Therefore, the law and regulations pertaining to SLPs need to be clear, enforced, and governable (Creative Space Media, 2015). Put differently, the Centre for Applied Legal Studies (CALS) 2017 report recommended wide-ranging policy and legislative changes to the SLP system, warning that in their absence the system is certain to remain exclusionary and ineffectual. A major problem identified in this process is 'participation'. Pivotal to a meaningful participation process is that notices are sufficient to reach the bulk of affected community members. CALS findings indicate that consultations either take place or are poorly publicized. In the 2017 report CALS indicates that this problem could be addressed if a robust public participation process with clear notice requirements tailored to the circumstances of communities were inserted into the legislative framework. Furthermore, in support of the 'participation' issue, CALS recommends a minimum requirement be set in legislation for consultation meetings between mining companies and communities. A critical facet to this, it is argueed, is for mining companies to be able to identify where in their institutional structure the responsibility for SLPS is located. This becomes important to establish clear lines of accountability and implementation of SLPs. In ensuring this, CALS believes that the DMR should intensify its enforcement of SLP obligations, making sanctions for noncompliance 'real'. The concern with this, however, is the widespread issue of lack of capacity within the DMR to regulate (and monitor) proper implementation of SLPs and therefore the lack of stakeholder engagement. This is a major impediment in the SLP system. A solution suggested by CALS is capacity building within DMR. In addition to this, one cannot ignore the fact that 'SLPs are implemented in the context of a constitutional allocation of powers and functions that includes distinct and overlapping roles by national, provincial and local spheres of government'. In this respect, CALS proposes that a framework be established for the cooperation of all organs of State with a key role in miningrelated governance and planning. There has been a shifting of responsibility regarding SLP problems, and legislation ought to be drafted to streamline responsibilities. For example clarity on the role of SLPS in relation to related persons (such as IDPS) pertaining to local economic development. (Centre for Applied Legal Studies, 2017).

Against this backdrop, in spite of these flaws and challenges of the SLP system, the amendment to Section 36(11)(e) of the Tax Act entitles a mining company to allowable deductions of 'capital expenditure' incurred on infrastructure in terms of SLP requirements as per the MPRDA. To this end, an interim solution could be to ensure that such deductions are dependent on concrete evidence provided by the mining companies that the SLPs have in fact been implemented, together with extensive consultation with the respective communities. This should be included in the Mining Charter Scorecard, or at the very least the extent of mine community development should have measurable goals to which mining companies can be held accountable. The Mining Charter 2018 definition of 'Mine Community Development' is a good place to start in establishing these measurable goals. This evidence could be in the form of documentation signed by the respective related parties affirming that SLPS have been implemented and that constructive consultation has taken place (and/or ongoing where necessary). One can only hope that at that stage the DMR has the capacity to verify such evidence. To the extent that there is noncompliance by mining companies in implementation of SLPs, such deduction should not be granted; and furthermore, a negative scoring and/ or penalties should be imposed by the DMR on such mining companies for noncompliance.

As it stands, the weaknesses in the system due to regulatory constraints on implementation and enforcement will collapse the very foundation upon which SLPs repose. If pursued within the current SLP system, the deductions in terms of Section 36(11) (e) will have adverse unintended consequences in relation to the governance of the SLP system and the State - whose role as a primary social service provider is already under scrutiny with regard to the implementation of SLPS, especially since the system was designed to redress the historical legacy of inequality by placing binding obligations on companies to ensure that mining benefits workers and communities. However, in its present form, the SLP system is incapable of achieving these objectives (Centre for Applied Legal Studies, 2017), and as such a deduction as per Section $36(11)$ (e) is clearly 'putting the cart before the horse'.

\section{References}

BusaccA, M. 2013. Corporate Social Responsibility in South Africa's Mining Industry: Redressing the legacy of apartheid. Claremont McKenna College. pp. 26-32. http://scholarship.claremont.edu/cgi/viewcontent cgi? article $=1631 \&$ context $=$ cmc_theses.

CAwood, F.T. 2004. The Mineral and Petroleum Resources Development Act of 2002: A paradigm shift in mineral policy in South Africa. Journal of the South African Institute of Mining and Metallurgy, vol. 104, no. 1. pp. 53-64.

Centre for Applied Legal Studies (CALS). 2017. The Social and Labour Plan Series. Phase 2: Implementation operation analysis report by the Centre of Applied Legal Studies. The University of the Witwatersrand.

Centre for Applied Legal Studies (CALS). 2016. The Social and Labour Plan Series. Phase 1: System design. Trends analysis by Centre of Applied Legal Studies. University of the Witwatersrand.

CLEGG, D. 2018. Income Tax in South Africa. par. 20.4

https://www.mylexisnexis.co.za/Index.aspx [accessed 25 November 2016].

Coulson, N., LedwaBA, P., and McCAllum, A. 2017. Building resilient companycommunity relationships: A preliminary observation of the thoughts and experiences of community relations practitioners across Africa. Journal of the Southern African Institute of Mining and Metallurgy, vol. 117, no. 1. pp. 7-12.

Creative Space Media. 2015. Tshikululu Research Report: The South African Mining Industry. CSI: The Human Face of Business. Lonehill, South Africa. pp. 6-9.

Finweek RepoRt. 2008. Unsafe behaviour is normal behaviour. Finweek, 28 February 2008. p. 91.

Hamann, R. 2003. Corporate social responsibility and its implications for governance: The case of mining in South Africa. Oikos Foundation for Economy and Ecology, St. Gallen, Switzerland.

Hamann, R. 2004. Corporate social responsibility, partnerships, and institutional change: The case of mining companies in South Africa. Natural Resources Forum, vol. 28, no. 4. pp. 278-290.

Jenkins, H. and Yakovleva, N. 2006. Corporate social responsibility in the mining industry: exploring trends in social and environmental disclosure. Journal of Cleaner Production, vol. 14, no. 3-4. pp. 271-84.

KLoppers, H. and du Plessis, W. 2008. Corporate social responsibility, legislative reforms and mining in South Africa. Journal of Energy and Natural Resources Law, vol. 26. pp. 91-119.

Koma, S.B. And KuYE, J.O. 2014. The synchronisation of Integrated Development Plan and local economic development policy in South African municipalities- A sine qua non for growth and development. African Journal of Public Affairs, vol. 7 , no. 1. https://repository.up.ac.za/handle/2263/41526

MunNiK, V. 2010.The social and environmental consequences of coal mining in South Africa-A case study. Environmental Monitoring Group, Cape Town, South Africa and Both ENDs, Amsterdam, The Netherlands. January 2010. pp. 8-9.

South AFRICA. 2016a. Taxation Laws Amendment Bill 17B 2016 (Draft). National Treasury. http://www.treasury.gov.za/public\%20comments/TLAB $\% 20$ and\%20TALAB\%202016\%20Draft/2016\%20Draft\%20Taxation\%20Laws\%20 Amendment\%20Bill.pdf [Accessed 25 November 2016].

South AfricA. 2016b. Explanatory Memorandum on the Draft Taxation Laws Amendment Bill 17B 2016. http://www.treasury.gov.za/legislation/bills/2016/ EM\%20on\%20the\%20Taxation\%20Laws\%20Amendment\%20Bill\%2017B\%20 of $\% 202016 . p d f$

South AfricA. 2002. Mineral and Petroleum Resources Development Act 2002. Government Gazette, vol. 448. pp. 5-122.

South Africa. 1996. Constitution of the Republic of South Africa, Act 108 of 1996.

South Africa. 1962. Income Tax Act, 58 of 1962.Section 36. 